REVIEW ARTICLE

\title{
The analysis of change in behavior and development: on some errors and possibilities to correct them
}

\author{
Janusz Trempała ${ }^{1}$, Jan Cieciuch ${ }^{2}$ \\ 1: Institute of Psychology, Kazimierz Wielki University, Bydgoszcz, Poland \\ 2: Institute of Psychology, The Cardinal Wyszyński University in Warsaw, Warsaw, Poland
}

\begin{abstract}
We aim to demonstrate that the understanding of behavior and development requires a better fit between methods to gather and analyze data and the dynamic nature of psychological phenomena. We argue that there are limits to the application of static designs of data collection in correlation design and to focusing on measures of central tendency when inferring on the complex processes of change in human behavior and development. We describe possible ways to correct the errors we make and to overcome the difficulties that we face when measuring change.
\end{abstract}

We conclude that there is a need to identify a comprehensive model of gathering and analyzing data that takes into account the observation period of the phenomena (shortand long-term research), the complexity of the studied form of activity (elementary and complex) and the situation/context of the measurement (well-defined situation and situation "at large").

KEY WORDS

behavior; change; development; time; dynamic approach

CORResPonding AUthor - Prof. Janusz Trempała, Institute of Psychology, Kazimierz Wielki University, 1 Staffa Str., 85-867 Bydgoszcz, Poland, e-mail: tremjan@ukw.edu.pl AUthors' CONTRIBUtion - A: Study design - B: Data collection - C: Statistical analysis - D: Data interpretation .

E: Manuscript preparation · F: Literature search · G: Funds collection

TO CITE THIS ARTICLE - Trempała, J., \& Cieciuch, J. (2016). The analysis of change in behavior and development: on some errors and possibilities to correct them. Current Issues in Personality Psychology, 4(2), 65-74.

RECEIVED 04.12.2015 - REVIEWED 01.04.2016 · ACCEPTED 19.04.2016 · PUBLISHED 03.06.2016 


\section{BACKGROUND}

In this article we posit that to understand numerous psychological phenomena and processes it is necessary to apply a dynamic approach in which it is the change that is analyzed. It is indeed a central claim of developmental psychology, but its application is much wider - we think that it is related to many, or even all, phenomena that are also the subject of other disciplines of psychology. The perspective of developmental psychology allows one to identify the difficulties that we need to face when trying to consider the dynamics of the phenomena, the analysis of which is not possible without taking into account the time when the changes take place. In this essay we indicate the errors in studying the dynamics, difficulties of such studies and the attempts to overcome them. We also suggest the perspective for further development of methods to study and analyze the change. Some of the described problems can be solved using the already available methods, but many other problems are currently unsolvable. We consider the current deliberations to be preliminary, as we are aware that we need a wider discussion on adjusting the methods of data collection and analysis to the dynamic nature of psychological phenomena.

\section{DYNAMIC APPROACH}

The assumption that behavior and development are dynamic is widely accepted among researchers, at least in their declarations. However, it does not translate into the practice of gathering and analyzing the data. More or less consciously we make many errors related to the lapse of time in which we study a given phenomenon.

There are three assumptions that are crucial for the deliberations that we present here: a) the essence of behavior and of development is not a state but its change - behavior and development are impossible without some change having occurred; b) the basic category of change analysis is time - changes take place in time and their measurement is not possible without considering the lapse of time; c) general laws of behavior and development are identical - from the formal perspective human behavior and development can be explained with similar factors.

The last assumption broadens the extent of discussion on psychological phenomena. From the dynamic perspective the common subject of psychological research is the genesis of processes, functions and mental activities. Its description and explanation (understanding) is the basis of prevention, correction and stimulation of patterns of successful human life.

When we talk about dynamism, students often ask what it is or what it means that the studied re- ality is dynamic. The simplest answer is that what we study changes. This answer usually suffices and the students accept the notion that the science of behavior and development must describe the laws according to which these changes take place. However, further discussion on the nature of these laws is not that simple. The phenomena are the function of various interrelated factors that comprise the complex mechanisms of change that we do not completely understand. Striving to explain this complexity, we often call upon the authorities, quote the theories that are widely accepted in the literature, or we manifest scientific skepticism, saying that currently not everything can be thoroughly studied and that we cannot understand all the rules according to which the observed changes occur.

For a few decades now many researchers have attached more importance to change. In order to capture the analysis of stability and change of the complex phenomena that we observe in nature in a cohesive framework, the researchers refer to the theory of dynamic systems. Derived from mathematics, it raises increasing interest in such diverse disciplines as physics, biology and also psychology (see Thelen \& Smith, 1994; Nowak \& Vallacher, 1998). In developmental psychology the pioneers of its application are Esther Thelen (Thelen \& Smith, 1994, 2006), Paul van Geert (van Geert, 1997, 2002) and Kurt Fischer (Fisher \& Bidell, 2006). Two rules are emphasized in this approach: a) each behavior is the result of many states/features of a person and the context; b) change is important information necessary to understand human behavior and development. Increasingly often another model is proposed: the dynamic model of interaction between the always changing person and the always changing environment as two complex and open systems (e.g., Lerner \& Hultsch, 1983; Magnusson \& Stattin, 2006). In this approach all components of functioning and development are included in the loop of multi-faceted and recurrent co-determinants (co-actions; see Gotlieb, 2003).

The emphasis on change and the complexity of dynamic systems does not mean that the studied reality is fluid and unpredictable. Researchers want to understand how the changes happen, leading to stable states towards which the system evolves or the stability of new forms of organization that the system achieves in development (Thelen \& Smith, 1994; Granott, Fischer, \& Parziale, 2002). This approach adopts new perspectives and requires a discussion on adjusting the methods of collecting and analyzing the data to the dynamic nature of mental phenomena. Demonstrating the complexity of the process of change shows the methodological difficulties in studying it as well as errors that we often make in psychology. One of the most basic mistakes is the static error in data measurement and analysis. 


\section{STATIC ERROR IN MEASUREMENT AND DATA ANALYSIS}

\section{THE ERROR}

The core of the static error is inferring about a given functioning, shaping or learning mechanism on the basis of a single measurement of variables (i.e., in a given measurement time $T_{1}$ ) and the statistical (static) correlations/differences/interactions between them, in line with the assumed theoretical model of the given phenomenon. In this process we obtain a "photograph" of the state/states at the time of their measurement based on which we infer the shape, functioning or the mechanism. We act like photographers who "capture in the frame" the phenomenon/ event that we are trying to explain based on a given theoretical assumption about the relationship between the studied "variables", i.e., the factors the parameters of which do not change in such measurement.

We usually solve the difficulties with studying the dynamics of the phenomena by building a theoretical model of the phenomenon assuming that the comprising factors "constitute" the shaping mechanism of an individual's behavior or development. Moreover, in order to characterize the dynamics of change we assume that some of the specified factors "do something", i.e., activate (e.g., stimuli, environment), guide (e.g., goals, values, needs) or condition (e.g., genes, neural pathways) the activity observed in the individual's behavior and development. We consider these factors to be the variables, and within the correlational model of research we look for their relationships/differences that were adopted in the assumed model of the given phenomenon. We interpret the identified correlations between these factors and an individual's behavior in line with the assumed model.

This error is typical for the correlation approach in which it is assumed that there is a mutual influence of specified factors. Unfortunately, it is assumed but not controlled in the research process.

We can also formulate the objection of measurement stability against other research designs applied in the psychology of human development, because not all of them deal well with the lapse of time. In developmental psychology, when we want to describe any time-related changes we usually implement the following research designs:

a) Outcome variable $\left(\mathrm{X}_{1-\mathrm{n}}\right) \times$ Age group $\left(\mathrm{Y}_{1-\mathrm{n}}\right)$;

b) Outcome variable $\left(X_{1-n}\right) \times$ Occasion $\left(Z_{1-n}\right)$;

c) Outcome variable $\left(\mathrm{X}_{1-\mathrm{n}}\right) \times$ Age group $\left(\mathrm{Y}_{1-\mathrm{n}}\right) \times$ Occasion $\left(Z_{1-n}\right)$.

In the first case we talk about cross-sectional studies in which we compare the average results of a single measurement of a given variable in different age groups, assuming that the between-group differenc- es are the function of differences in the participants' age. The second case represents longitudinal studies in which we compare the average results of a given variable at subsequent points in time (occasions, according to Cattell's data box), assuming that differences are the function of the time lapse between the measurement points. The last case refers to the sequential analysis in which - generally speaking from the sum of measurement differences we "subtract" the differences between the average results of longitudinal measurement and the average results of cross-sectional measurement in the age groups, assuming that the "residual" allows one to assess the so-called pure effect of age in the studied variability.

Cross-sectional studies are most often used in developmental psychology. This happens despite the fact that since the times of Schaie (1965) we know that it is the weakest design (the least accurate). It is understandable why it is so popular. This design is "fast" and "the cheapest" but carries an important error: we do not separate the result of between-cohort changes from the effect of participants' age. Today we know for example about the Flynn effect (Flynn, 1987; see Raven, 2000); Flynn was the first to demonstrate that when measuring intelligence in successive cohorts/age groups we observe a statistically significant increase in ability. Therefore, the assumption at the basis of cross-sectional design, according to which the differences obtained in the measurement of the variables in the age groups are only the function of the differences in participants' age, is not correct. Thus, inferring about developmental changes when using this research design is not valid.

\section{ERROR CORRECTION: LONGITUDINAL STUDIES}

The classic response from the methodology of development research to the above described problem is the longitudinal design in which the same people are tested at the time intervals appropriate for the given research subject. It is an increasingly popular way to study the dynamic complexity of psychological phenomena and to follow short- or long-term trajectories of changes in observed activity and at the same time to follow the changes in environmental and biological conditions. The presence of changes and their sequence in time are interpreted from the perspective of mutual influence that explains the genesis of the observed behavior.

Despite the high cost of longitudinal studies (organizational, financial and time-related), there are a few arguments that justify their implementation (see e.g., van der Kamp \& Bijleveld, 2002; Trempala \& Olejnik, 2011). The first and the most convincing argument is that when we want to study the change of a given activity the only way is to repeat the mea- 
surements. We cannot register changes of e.g. acquiring new skills, knowledge or new organization of behavior without repeating their measurements. Secondly, change or the temporal order of events enables the analysis of causality between the variables. Namely, it is the necessary (but not sufficient) condition for testing the hypotheses of causality. The basis for inferring about causality is the sequence of events. Third, longitudinal design allows for describing both the between-person and within-person changes that happen with time. As a result, and in contrast to cross-sectional studies, not only can we assess the size of changes but also we obtain information about the inter-individual variability in the patterns of changes throughout the study.

Data gathered in longitudinal studies contain the necessary information, but it is not always easy to extract them. Unfortunately, even when the researchers dispose of the data gathered at various points in time, they encounter a few methodological issues related to e.g. missing data in the sample or serial dependency of repeated measurements that prevent them from using many statistical tests. Even when these obstacles have been overcome, the researchers still - in our opinion - face equally serious but less often discussed problems. In the following parts of this essay we want to address some issues related to focusing the data analysis on central tendencies and to the time intervals between measurements.

\section{PROBLEM 1. THE ERROR OF CENTRAL TENDENCIES IN LONGITUDINAL STUDIES}

\section{THE ERROR}

The core of this error ${ }^{1}$ is inferring about the laws of behavior and development from average scores obtained on a given variable or variables among different groups of study participants or in different situations and at different times of measurement (occasions). For instance, when we are interested in an isolated mental function (e.g., perception, memory, empathy) we usually look for the central tendency in the level of the given variables in the group(s) or situation(s) at different measurement times (occasions). When we are interested in the patterns of relationships between different functions we compare their average scores in different group(s) and/or measurement times.

However, we forget about two important issues. First, the result of such analyses is stochastic and is only an assessment of the probability of a given rule's presence in the studied reality. In such a process we treat standard deviations as measurement error and - when we find a statistically significant tendency often omit them in further analyses (considering them information without much significance). Secondly, the result of this assessment is the result of the raw data transformation within the framework of static models that assume their specific nature (i.e., linearity, continuity, stability). It can be added that usually the more complex the models of statistical analysis are, the greater are the transformations applied to the raw data. The representation of the principles agreed on in such a way and considered common and repetitive is thus doubtful.

These doubts increase when we sometimes watch more closely the distribution of raw scores obtained by the study participants for the measure of a given variable. We then predominantly notice that the participants differ from each other and that, at most, we can see some clusters of people who score similarly but not identically on a given variable. Then, we come to a conclusion - a surprising one if we take the perspective focused on central tendencies - that in the studied reality there is no "average person" or "average environment”. Kurt Lewin (1931) pointed this out over 80 years ago. Currently, using computer modeling, we can demonstrate that often among the participants we cannot find even one person whose scores would be identical with the average score, the computer-calculated change (see e.g., Molenaar, Huizenga, \& Nesselroade, 2002).

Therefore, it is difficult to sustain the notion that there is some "average" pattern of mechanism, shaping or functioning. It seems then that the concept of central tendency is abstract and has limited application in the analysis of human behavior and development.

\section{ERROR CORRECTION: THE ANALYSIS OF INTER- AND INTRA-INDIVIDUAL DIFFERENCES}

The identified error can be, at least partially, eliminated in the analyses that take into account the inter-individual variability. To analyze the results of longitudinal studies we can use the latent growth curve (LGC) model, in particular when combined with the latent class analysis. The first step is to distinguish two types of change: mean-level change and individual level change (Biesanz, West, \& Kwok, 2003). The first one is related to the change at the group level, the average change which - as we demonstrated earlier - is problematic. The second change is related to an individual change that can be defined as the difference between changes in particular individuals and the average change. If this variability is small then it means that the participants change in a similar way. Large variability, on the other hand, means that there are different change patterns. The LGC model provides information both about the average change and the inter-individual variability (Bollen \& Curran, 2006; Duncan, Duncan, \& Strycker, 2006). 
In the LGC model the individual change is the function of three elements, similarly to the regression analysis, but here each of the elements is a latent variable. These three elements are: 1) the latent intercept factor, which is the baseline variable level, 2) the latent slope factor, which represents the mean change, and 3) the error (Bollen \& Curran, 2006). In this approach the indicator of the change at the group level is the mean of the slope, whereas the indicator of the inter-individual variability in this change is the variance of this latent variable.

The LGC model is in fact a special case of a confirmatory factor analysis. The observed variables are the results concerning the level of the tested variable in successive measurements and the latent variables are the intercept and slope. Similarly to factor analysis, there have to be at least three measurements of the observed variable and there is no upper limit on their number. Unlike confirmatory factor analysis, all of the factor loadings are determined by the researcher, who is only interested in the means and standard deviations of latent variables, in particular those of the slope. The decision concerning the loadings is based on the researcher's hypothesis on the nature of the trend. LGC allows for testing not only of linear but also curvilinear models (Byrne, 2010).

From the perspective of these considerations, the most important information is provided by the variance of the slope. We must note that it is only binary information. We only find out whether there is significant variation of the individual change trajectories compared to the group average. Information about the existence of such variability is therefore important information, but at the same time insufficient. Such information instantly generates more questions about the specificity of this differentiation. There are two analytical ways to look for answers to this question. The first one - similarly to the LGC model - is the variable-centered approach, and the second one overpasses this paradigm towards the person-centered approach.

In the first approach this inter-individual variation can be explained, and in the other one we can try to describe it (which, of course, does not exclude an attempt to explain it in the next step). Explanation in the first approach means introducing a different variable into the model; a variable that - according to the researcher's hypothesis - could explain the inter-individual variability, the indicator of which is the variation of the slope. The advantage of such an approach is the clear indication of whether a given external variable (e.g., sex, or some other demographic or psychological characteristic) is responsible for this variation. The disadvantage of this approach is that the researchers need to have those variables in their database, while they are often not only unavailable but also there are not even theoretical suspicions of what those variables might be.
The description in the second approach lies in thinking in terms of latent classes. This tradition in psychology is linked to such authors as, among others, Block (1971) and Magnusson (1998) and recently developed from the methodological perspective by, among others, Lubke and Muthén (2005). In this approach it is assumed that the studied sample is non-homogeneous, but the division criterion is latent. The combination of LGC analysis and latent class analysis allows one to identify subgroups of people with the same course of change. The advantage of this approach is that it allows one to reduce the error of the central tendency as only subgroups of people similar in a certain way are identified. This approach does not eliminate the error of the central tendency but certainly minimizes it. Moreover, one can hope that the development of methods in this area will lead to the creation of precise measures of this error. More precise information about the size of the error would be very useful in a situation when the error cannot be completely eliminated.

\section{PROBLEM 2. IGNORING THE RELATIONSHIPS BETWEEN MICRO- AND MACRO-CHANGES IN LONGITUDINAL STUDIES}

Longitudinal studies, conducted intensely, with multiple measurements, can provide results that are interesting but difficult to synthesize. This poses a problem of comparing and/or reducing data that come from short- and long-term longitudinal studies. The problem is even greater if the study concerns functions of varying complexities: elementary and more global changes in human behavior and development. Doing so, we usually assume that those changes are subject to the same rules. However, when looking more into this issue, numerous doubts arise.

For example, in developmental psychology, microgenetic changes are often treated as general developmental models, in accordance with the classical suggestions of Gesell (1946) or Werner (1957). However, we know today that the micro- and macro-developmental models describe different patterns of change in human behavior. In the first case, we usually study the relatively short changes of the simple forms of activity under direct observation. In the early and late phases of ontogeny they are clear and linked to temporal patterns of maturation and ageing. However, when we examine the relatively long-term changes of the more complex processes or functions, the picture of the development is not so clear anymore: the changes are not so strongly related to age, and they show an increase of the individual differences (Trempala, 2011).

This problem is also visible in other areas of psychological research. This is always the case when 
comparing data that differ in the observation time (long- and short-term), the size of the observable behavior (elementary and more complex forms of activity) and finally, in different contexts (in a laboratory situation and in "any" situation, not always well defined). Every time we have to deal with the varying nature of data, which is closely related to the method of collection.

This problem was noticed 70 years ago by Kurt Lewin (1946). He noted that human behavior (and development) is studied at two different levels: microscopic and macroscopic. According to his suggestions, we can say that at the first of those levels, we study short-term changes (measured in milliseconds, seconds, minutes and hours) concerning the elementary reactions and activities (e.g., reaction time, eye movement, syllable discrimination), in a well-defined situation (usually in a laboratory or experimental setting). In the second case, we study more long-term changes (days, weeks, months or years), usually concerning more complex forms of activity (e.g., understanding, learning of a text or a role, development of a career or a path of life) and in natural conditions, life situations or the situation at large $e^{2}$. Lewin asked the alarming question whether the results from those two levels can be reduced to one another. This question has still not been answered decisively.

Traditionally, this distinction corresponds to a strong opposition of macrodevelopmental and microdevelopmental studies in developmental psychology. However, the answer to the question about the relationship between the micro- and macro-changes is not clear (see review by Granott \& Parziale, 2002; Siegler, 2006).

For example, Gesell (1946) suggested that the rules of change of the elementary psychomotor functions in infants (e.g., catching a ball) that he discovered can be extended to human functioning in general. Werner (1957), the founder of the so-called microgenetic method, believed - in fact similarly to Vygotsky (1989) - that short-term changes are a model for long-term changes, and that the same rules of creation of change lie at their core. In contrast, Piaget (1977) expressed an original view on the matter. He believed that short- and long-term changes are not similar. He thought that the former are linked to learning and the latter to development. He justified this lack of similarity by the fact that development creates new cognitive structures and learning fills them with content, being responsible for - as we say - horizontal development.

The dispute over the nature and relations between micro- and macro-developmental changes continues also today. It is difficult to coherently summarize different positions on the subject. Even the supporters of the microgenetic method are not certain today if their research provides convincing evidence that a systematic analysis of short-term changes provides a documentation of reintegration of the learning and developmental processes (which have fewer differences than similarities) into one general process (see e.g., Siegler, 1996; Kuhn, 2002; Lee \& Karmiloff-Smith, 2002). Some of them seem to favor the skeptical opinion expressed a long time ago by Lewin that the micro- and macro-changes cannot be reduced to one another (see e.g., Fischer \& Bidell, 2006). It is not just that the reliability of some of the microgenetic studies is uncertain, but also, or rather mainly, because they are concentrated on short-term change processes that the macrodevelopmental studies, conducted in longer intervals, are unable to capture. This does not mean that micro- and macro-developmental data do not complement each other (see e.g., Kuhn, 1995; Fischer \& Yan, 2002).

In this context, it is worth considering the correctness of generalizing the results of the microgenetic research to behaviors and human development in general. We are not trying to say that it is not possible to generalize the microgenetic rules to the macrogenetic ones and vice versa. However, this requires theoretical and methodological precautions, which are often lacking in research practice, and the effect of which is the error of unauthorized merging of conclusions from the research on micro- and macro-changes.

\section{PROBLEM 3. IGNORING THE EFFECT OF THE LAPSE OF TIME IN LONGITUDINAL STUDIES}

There can be another problem concerning longitudinal studies, which originates from disregarding the dynamic nature of the studied phenomena or from more or less conscious ignoring of the effect of the time lapse when measuring the variables that are of interest. This problem is found in some methodological claims and widespread research practice. Obvious examples can be found in two such cases on which we want to focus in this paper, so as not to go into a more detailed discussion.

The problem of replication as a criterion of scientific reliability. We replicate research because of a belief that the confirmation of a certain result in a repeated study is a proof of its existence in the studied reality. The problem is that replication of research concerning changes in behavior and human development is not always justified and sometimes it is just technically impossible to carry out.

For example, in developmental psychology we are interested not only in short-term changes but also in those that take more time, that last years or even decades. Replication of longitudinal studies in order to confirm the obtained results is basically impossible. The researcher can plan a study so that it will concern only the same age groups, but not the same 
cohorts (people born in the same year). The mistake of treating as equivalent the results of research on people of the same age but gathered in different historical and social periods was noted a long time ago by the already mentioned Schaie (1965). Since then, if we repeat a study in subsequent cohorts/among people born in the same year, it is not in order to validate the previous findings, but mostly to observe the so-called diagonal effects, i.e. the stability and variability of a given state/characteristic in successive generations. The recommended self-replications (see SMART: Systematically Modified Replications; Wojciszke, 2004), i.e., replications by the same researcher or the same team, are - in the case of longitudinal studies - usually technically impossible to carry out. They require the participation of several generations of researchers and a constant source of financing.

A good example of failures in replication is the recently published research results of Nosek (2015), whose team set out to replicate over a 100 published psychological experiments and correlational studies. It turned out that only one in three studies gave the same results. Those results should not be surprising in the view of the above observations. It seems that beside other causes of failures in replicating research results, the problem of time lapse requires more attention.

The problem of measurement stability as a criterion of internal validity. Generally speaking, stability means the stability of measurement of a variable(s) in time, i.e., in different age groups (cross-sectional studies) or at different time points (longitudinal studies). Stability analyses usually concern the differences between the mean levels of severity of the conditions/features (absolute stability) and the differences between individuals in this regard (relative stability), as well as their covariance (structural stability). This criterion is used to measure both the reliability (understood as stability) and the construct validity (e.g., intelligence or personality traits). For the reliability measure, the test-retest procedure is usually used, i.e., repeating the measurement with a tested tool in the same group of participants (usually within a few weeks). Generally, we assume that reliability is greater the higher is the correlation between the first and the repeated measurement, and the validity depends on the theoretical assumptions.

A literature review of the stability models does not show a very coherent picture of the changes that occur in human behavior and development (see e.g., Baltes, Lindenberger, \& Staudinger, 2006; Olejnik, 2011). The dominant idea is that the traits, as a basic disposition from the three-level model of McAdams, are stable throughout one's life, unlike the characteristic adjustments (adjustment style, values, emotions) or the self-concept from the third level of personality (McAdams, 1995, see Oles, 2003), which undergo significant changes, including developmental ones.
Most of the inconsistencies of the published data come from comparing the research results that "mix" those levels, and also come from different development designs: cross-sectional and longitudinal ones. The first of these, although widely used, come with the largest error and are the least valid. But problems also arise from the results of longitudinal studies concerning the stability, which we find increasingly often in the literature.

For example, some time ago there was an impressive meta-analysis of data from 152 longitudinal studies (the test-retest type) published between 1938 and $1999(N=55180)$ conducted by Roberts and DelVecchio (2000). They found change with age of the ranked compatibility coefficients of the participants' personality traits: from 0.31 in early childhood, to 0.64 by the end of early adulthood, and up to 0.74 after 50 years of age. Those results showed that the older the person, the more probable it is that their traits will remain stable. However, the most surprising result shows that from the age of 50 , the correlation coefficients of repeated measurements (test-retest) are much lower than the reliability coefficients of the commonly used diagnostic scales, which are usually higher than 0.70 (see e.g., Eliasz \& Klonowicz, 2003). This ceases to surprise when, after a careful analysis of this meta-analysis, we realize that the classical discussion of the problems concerning longitudinal studies (such as dropouts from the sample, learning, time passed between measurements) is not enough to interpret those results. The data put into this meta-analytical "pot" came from research concerning correlation of measurements repeated in different historical and social time, among people at a given age born in different cohorts ${ }^{3}$.

The above examples show that the lack of serious consideration of the effects of the time lapse on the measurement of variables can produce artefacts and lead to empirical statements that are non-permanent or impossible to explain. It seems that when taking on the task of replicating studies or using repeated measures in order to estimate the reliability of a test (measurement's stability), we need to determine which components of the studied change are related to the time lapse, and separate them from those that are unrelated to the time lapse.

\section{PERSPECTIVES: WHAT METHODS ARE NEEDED FOR THE PSYCHOLOGY THAT ANALYSES CHANGE?}

The above considerations show that psychology needs methods of data collection and analysis that are better suited for the dynamic nature of the phenomena we study. The answer about the nature of this better fit is not simple and requires discussion. What are our conclusions? 
First of all, when seeking to answer the question about how the changes in human functioning and development happen, we conclude that what is needed is observation of the phenomenon in question in time (i.e., avoiding the static error), which equals the need to repeat the measures at different points in time.

Secondly, concentrating the longitudinal research on variables and measures of central tendency limits the insight into the inter-individual differences and individual patterns of change, which cannot be equated with the measurement error and treated as information pollution that disturbs regularities (which we pointed out in Problem 1 that is related to longitudinal studies).

Third, longitudinal data collected at various time intervals, when measuring functions of different complexity and in different situations (contexts), require different methods and have different nature, which makes it difficult to compare them with each other and, even more, reduce them to one another (which we saw as Problem 2 of longitudinal studies).

Fourth, repeating measurements (e.g., when conducting replications or in test-retest studies to evaluate the measurement stability for a given tool) may lead to inference artefacts if the changes related and unrelated to the passage of time are not separated (which we discussed as Problem 3 of longitudinal studies).

Overall, the conclusions from this discussion are the following: a) while the static error can be fixed by using longitudinal research designs for the variables of interest, and b) Problem 1, related to the analysis of longitudinal data concentrated on the measures of central tendency, can be tackled using growth curve models, c) Problems 2 and 3 are not easily solvable without considering a vast number of possible influences potentially crucial for the description and explanation of the observable change.

Therefore, we humbly admit that at the present we are unable to clearly identify possible solutions to Problems 2 and 3. On one hand, we demonstrated that when conducting longitudinal studies the researchers make different assumptions about the effects of repeating the measurement, and sometimes they just simply ignore the issue of the passing time. While we have no doubts that ignoring the time of measurement does not allow one to infer about the dynamics of the studied phenomenon, we do not yet possess the knowledge to unambiguously resolve whether the assumptions made in the literature concerning the nature of changes and the way to measure change (operationalization of what we call the change) are correct. On the other hand, we showed that in the change analysis, beside the period of its observation (short- and long-term research), the complexity of the studied form of activity and the contexts (situation) of the measurement are important. Our thoughts on the micro- and macro-changes in human behavior and development suggest that in the field of psychology we collect data of a different nature using different methods. We conclude that there is a need to look for a synthesis of those two approaches, within the framework of a comprehensive data collection model and the methods of their analysis. We posit this with a strong conviction that finding such a model will make it easier to find the answers to questions pertaining to the general principles concerning human functioning and development.

\section{ENDNOTES}

1 We want to stress that the analysis of central tendencies is not an error by itself. We talk about the reduction error of phenomenon description to the central tendencies.

2 When analyzing the legacy of modern psychology, especially in the Neo-Piagetian approach, we can add that in the studies that Lewin calls microscopic, we usually concentrate on the process of "changing" of a phenomenon while it is being studied, while in macroscopic studies we concentrate more on the "consequences" of a longer-lasting process/transformation process.

3 It is likely significant that different age groups do not represent evenly the people born in different years/cohorts, because, e.g., the problem of stability during the aging period only started to be studied recently.

The work of Jan Cieciuch was supported by Grants 2014/14/M/HS6/00919 from the National Science Centre, Poland.

\section{REFERENCES}

Baltes, P. B., Lindenberger, U., \& Staudinger, U. (2006). Life span theory in developmental psychology. In W. Damon \& R. M. Lerner (eds.), Handbook of child psychology. Vol. 1. Theoretical models of human development ( $6^{\text {th }}$ ed., pp. 569-664). Hoboken, NJ, US: John Wiley \& Sons Inc.

Biesanz, J. C., West, S. G., \& Kwok, O. M. (2003). Personality over time: Methodological approaches to the study of short-term and long-term development and change. Journal of Personality, 71, 905-941.

Block, J. (1971). Lives through time. Berkeley: Bankroft Books.

Bollen, K. A., \& Curran, P. J. (2006). Latent curve models: A structural equation perspective. Hoboken, NJ, US: Wiley.

Byrne, B. (2010). Structural equation modeling with AMOS. Basic concepts, applications and programming. New York, NY, US: Routledge/Taylor \& Francis Group. 
Duncan, T. E., Duncan, S. C., \& Strycker, L. A. (2006). An introduction to latent variable growth curve modeling: Concepts, issues, and applications ( $2^{\text {nd }}$ ed.). Mahwah, NJ, US: Lawrence Erlbaum Associates Publishers.

Eliasz A., \& Klonowicz T. (2003). Zewnętrzne i wewnętrzne czynniki destabilizujące system regulacji stymulacji [External and internal factors that destabilize the regulation and stimulation system]. Kolokwia Psychologiczne, 11, 109-134.

Fischer, K. W., \& Bidell, T. R. (2006). Dynamic development of action and thought. In W. Damon \& R. M. Lerner (eds.), Handbook of child psychology. Vol. 1. Theoretical models of human development (6 $6^{\text {th }}$ ed., pp. 313-399). Hoboken, NJ, US: John Wiley \& Sons Inc.

Fischer, K. W., \& Yan, Z. (2002). Darwin's construction of the theory of evolution: microdevelopment of explanations of variation and change in species. In N. Granott \& J. Parziale (eds.), Microdevelopment: Transition processes in development and learning (pp. 294-318). New York, NY, US: Cambridge University Press.

Flynn, J. R. (1987). Massive IQ gains in 14 nations: What IQ tests really measure. Psychological Bulletin, 101, 171-191.

Gesell, A. (1946). The ontogenesis of infant behavior. In L. Carmicheal (ed.), Manual of child psychology (pp. 295-331). Hoboken, NJ, US: John Wiley \& Sons Inc.

Gotlieb, G. (2003). Probabilistic epigenesist of development. In J. Valsiner \& K. J. Connoly (eds.), Handbook of developmental psychology (pp. 3-17). Thousand Oaks: Sage.

Granott, N., Fischer, K. W., \& Parziale, J. (2002). Bridging to the unknown: $A$ transition mechanism in learning and development. In N. Granott \& J. Parziale (eds.), Microdevelopment: Transition processes in development and learning (pp. 131-156). New York, NY, US: Cambridge University Press.

Granott, N., \& Parziale, J. (2002). Microdevelopment: A process-oriented perspective for studying development and learning. In N. Granott \& J. Parziale (eds.), Microdevelopment: Transition processes in development and learning (pp. 1-30). New York, NY, US: Cambridge University Press.

Kuhn, D. (1995). Microgenetic study of change: What has it told us? Psychological Science, 6, 133-139.

Kuhn, D. (2002). A multi-component system that constructs knowledge: Insight from microgenetic study. In N. Granott \& J. Parziale (eds.), Microdevelopment: Transition processes in development and learning (pp. 109-130). New York, NY, US: Cambridge University Press.

Lee, K., \& Karmiloff-Smith, A. (2002). Macro- and microdevelopmental research: Assumptions, research strategies, constraints, and utilities. In N. Granott \& J. Parziale (eds.), Microdevelopment:
Transition processes in development and learning (pp. 243-268). New York, NY, US: Cambridge University Press.

Lerner, R. M., \& Hultsch, D. F. (1983). Human development: A life-span perspective. New York: McGraw Hill Book Company.

Lewin, K. (1931). The conflict between Aristotelian and Galileian modes of thought in contemporary psychology. Journal of General Psychology, 5, 141-177.

Lewin, K. (1946). Behavior and development as a function of total situation. In L. Carmicheal (ed.), Manual of child psychology (pp. 791-844). Hoboken, NJ, US: John Wiley \& Sons Inc.

Lubke, G. H., \& Muthén, B. (2005). Investigating population heterogeneity with factor mixture models. Psychological Methods, 10, 21-39.

Magnusson, D. (1998). The logic and implications of a person-oriented approach. In R. B. Carins, L. R. Bergman, \& J. Kagan (eds.), Methods and models for studying the individual (pp. 33-62). Thousand Oaks: Sage.

Magnusson, D., \& Stattin, H. (2006). The person in context: a holistic-interactionistic approach. In W. Damon \& R. M. Lerner (eds.), Handbook of child psychology. Vol. 1. Theoretical models of human development (pp. 400-515). Hoboken: John Wiley \& Sons.

McAdams, D. P. (1995). What do we know when we know a person? Journal of Personality, 63, 365-396.

Molenaar, P. C. M., Huizenga, H. M., \& Nesselroade, J. R. (2002). The relationship between the structure of inter-individual and intra-individual variability: A theoretical and empirical indication of developmental system theory. In U. M. Staudinger \& U. Linderberger (eds.), Understanding human development (pp. 339-360). Dordrecht: Kluwer Press.

Nosek, B. (2015). Estimating the reproducibility of psychological science. Science, 349 (6251).

Nowak A., \& Vallacher R. R. (1998). Dynamical social psychology. New York, London: The Guilford Press.

Olejnik, M. (2011). Średnia dorosłość [Middle-adulthood]. In J. Trempała (ed.), Psychologia rozwoju człowieka [Psychology of human development] (pp. 312-327). Warsaw: Wydawnictwo Naukowe PWN.

Oles, P. K. (2003). Wprowadzenie do psychologii osobowości [Introduction to Psychology of Personality]. Warsaw: Wydawnictwo Naukowe Scholar.

Piaget, J. (1977). Psychologia i epistemologia [Psychology and epistemology]. Warsaw: PWN.

Raven, J. (2000). The Raven's Progressive Matrices: change and stability over culture and time. Cognitive Psychology, 41, 1-48.

Roberts, B. W., \& DelVecchio, W. F. (2000). The rank-order consistency of personality traits from childhood to old age: A quantitative review of longitudinal studies. Psychological Bulletin, 126, 3-25. 
Schaie, K. W. (1965). A general model for study of developmental problems. Psychological Bulletin, 91, 133-141.

Siegler, R. S. (1996). Emerging minds: The process of change in children's thinking. New York: Oxford University Press.

Siegler, R. S. (2006). Microgenetic analyses of learning. Dynamic development of action and thought. In W. Damon \& R. M. Lerner (eds.), Handbook of child psychology. Vol. 2. Theoretical models of human development (pp. 464-510). Hoboken: John Wiley \& Sons.

Thelen, E., \& Smith, L. B. (1994). A dynamic systems approach to the development of cognition and action. Cambridge: MIT Press.

Thelen, E., \& Smith, L. B. (2006). Dynamic system theories. In W. Damon, \& R. M. Lerner (eds.), Handbook of child psychology. Vol. 1. Theoretical models of human development (pp. 258-312). Hoboken: John Wiley \& Sons.

Trempala, J. (2011). Natura rozwoju psychicznego [The nature of psychological development]. In J. Trempala (ed.), Psychologia rozwoju człowieka [Psychology of human development] (pp. 28-49). Warsaw: Wydawnictwo Naukowe PWN.

Trempala J., \& Olejnik M. (2011). Badanie rozwoju psychicznego człowieka [Studying human psychological development]. In J. Trempala (ed.), Psychologia rozwoju człowieka [Psychology of human development] (pp. 127-144). Warsaw: Wydawnictwo Naukowe PWN.

van Geert, P. (1997). Variability and fluctuations: A dynamic view. In E. Amsel \& K. A. Renninger (eds.), Change and development: Issues of theory, method, and applications (pp. 193-212). Mahwah: Erlbaum.

van Geert, P. (2002). Developmental dynamics, intentional action, and fuzzy sets. In N. Granott \& J. Parziale (eds.), Microdevelopment. Transition processes in development and learning (pp. 319343). Cambridge: Cambridge University Press.

van der Kamp, L. J. Th., \& Bijleveld, C. C. J. (2002). Methodological issues in longitudinal research. In C. C. J. H. Bijleveld, Th. Van der Kamp, A. Mooijaart, W. A. van der Kloot, R. van der Leeden, \& E. van der Burg (eds.), Longitudinal data analysis. Designs, models, and methods (pp. 1-45). London: Sage Publications.

Werner, H. (1957). The concept of development from a comparative and organismic point of view. In D. B. Harris (ed.), The concept of development (pp. 125-147). Minneapolis: University of Mineapolis Press.

Wojciszke, B. (2004). Systematycznie modyfikowane autoreplikacje: logika programu badań empirycznych w psychologii [Systematically modified replications: the logics of the empirical research in psychology]. In J. Brzezinski (ed.), Metodologia badań psychologicznych. Wybór tekstów [Methodology of psychological research. Readings] (pp. 44-68). Warsaw: Wydawnictwo Naukowe PWN.

Vygotsky, L. S. (1989). Myślenie i mowa [Thinking and Speech]. Warsaw: PWN. 